\title{
Use of Genomic Approaches in Understanding the Role of Actinomycetes as PGP in Grain Legumes
}

\author{
Mamta Sharma, Avijit Tarafdar, and Raju Ghosh
}

\begin{abstract}
The advancement in molecular technologies has given a breakthrough to explore the untapped and novel microbial isolates for characterization in every aspect as we can consider microbes as an important primary natural store house for key secondary metabolites and enzymes. Actinomycetes are the most fruitful source of microorganisms for all types of bioactive secondary metabolites, including agroactive-antibiotic molecules that are best recognized and most valuable for their role in agriculture and industries. In agriculture, actinomycetes are used as biocontrol agents against some pests and pathogenic organisms as well as plant growth-promoting (PGP) agents for crops. Use of different molecular methods, e.g., metagenomics, metatranscriptomics, genetic fingerprinting, proteogenomics, and metaproteomics, are more significant for classifying and discovering the immense diversity in microbial population and for understanding their interactions with other abiotic and biotic environmental elements. The opportunity of accessing inexpensive sequencing techniques has led to the assemblies of copious genomic data for actinomycetes, such as Streptomyces and related species, with the goal of discovering novel bioactive metabolic and their utility as PGP; however, the use of actinomycetes in agriculture using genomic approaches is in its initial stages.
\end{abstract}

\section{Keywords}

Actinomycetes - Plant growth-promotion - Grain legumes - Whole genome sequence $\bullet$ Molecular technologies

M. Sharma $(\bowtie) \cdot$ A. Tarafdar $\bullet$ R. Ghosh International Crops Research Institute for the Semi-Arid Tropics (ICRISAT), Hyderabad, Telengana 502 324, India

e-mail: mamta.sharma@cgiar.org

\subsection{Introduction}

The analysis of microbial communities with the recent advances in culture-independent molecular techniques, including sequencing 
technologies and genomics information, has begun a new era of microbial ecology. Multiple techniques in molecular approaches based on direct analysis of lipids, proteins, and nucleic acids from environmental samples have uncovered structural and functional information about microbial communities. Molecular techniques, such as genetic fingerprinting and whole genome sequencing (WGS), are important tools for discovering, characterizing the diversified microbial population, and understanding their chemistry with other abiotic and biotic factors in environs.

Molecular and advanced technologies have a massive role in investigating the knowledge by exploring the actinomycetes across the microbial world. Advancement of WGS has made a scientific breakthrough, which unchains the understanding of latent biochemical and molecular topographies of uncultured microbe present in composite environs. The tactic of WGS of microbes bare the chemistry of the cryptic clusters of biosynthetic-related genes that are sometimes present but hidden, because those are not well recognized for producing any bioactive secondary metabolites (Fraser et al. 2002). In recent days, a total number of six genera of actinomycetes viz. Corynebacterium, Mycobacterium, Arthrobacter, Frankia, Rhodococcus, and Streptomyces have enough information about complete genome sequences to extemporize the core analysis of potential secondary metabolite and gene diversity (James and William 2013). Utilizing inexpensive sequencing techniques has led to the gathering of enormous genome sequencing data for Streptomyces and related species (Liu et al. 2013) with the goal of discovering novel bioactive metabolites. This chapter summarizes recent progress in the potential applications of actinomycetes using genomic approaches in agriculture. How they can be combined for a comprehensive evaluation of actinomycetes has been illustrated with example studies.

\subsection{Role of Molecular Approaches for Identification of Actinomycetes}

For identification and characterization of any biological organism, nucleic acid-based molecular approach is considered the most powerful approach and provides significant information about the organisms and the relationship with others (Kumar et al. 2014a). In past decades, classification and identification of organisms by approach of molecular systematics was based on nucleic acid hybridization studies. Gradual introduction of nucleic acid-based sequencing techniques in molecular systematics has been proved to be authentic (O'Donnell et al. 1993).

Following the polymerase chain reaction (PCR) technology, for better separation of the PCR products in polyacrylamide matrix, ureaformamide denaturing gradient gel electrophoresis (DGGE) (Myers et al. 1985) and temperature gradient gel electrophoresis (TGGE) (Riesner et al. 1989) were well adapted in the laboratory for studying microbial ecology. Later, for getting a sequence-based DNA fingerprint of microbial populations, temperature gradient gels were found to be quite promising (Muyzer 1999). Heuer et al. (1997) used DGGE and TGGE to study the genetic diversity of actinomycetes in different soils and to monitor shifts in their abundances in the potato rhizosphere. They used actinomycetes group-specific primers for the direct amplification of $16 \mathrm{~S}$ rDNA and an indirect nested PCR approach using a forward actinomycetes group-specific primer and a reverse bacterial primer, followed by PCR with two bacterial primers. Use of DGGE or TGGE of the products obtained with the nested PCR made it possible to estimate the abundance of the actinomycetes populations relative to the abundance of the other bacteria present in the soil.

Sequence of $16 \mathrm{~S}$ rDNA in systematic as well as phylogenetic studies of actinomycetes and 
other bacteria is another most commonly used approach. Primarily, the study of identification and evolution of actinomycetes based on $16 \mathrm{~S}$ rDNA has been initiated by amplifying the $16 \mathrm{~S}$ rRNA gene implying PCR strategy and followed by direct sequencing of amplified DNA fragments (Shiva 2001). Generally, thereafter, the obtained sequences are further explored in global database using bioinformatics tools to find out the identity and genetic information of query sequence if available, followed by analysis of phylogenetic correlation which reveals the identification of the actinomycetes up to the genus level and an overview on evolutionary aspect.

In a study by Intra et al. (2011), 16S rRNA gene sequences were used to identify the diversified actinomycetes groups exists in a collection of environmental samples. Detailed comparison of 16S rRNA gene of 30 actinomycetes isolates determined that majority of the isolates $(87 \%)$ within the environmental samples belong to the genus Streptomyces spp., whereas one each belongs to Saccharopolyspora and Nocardiopsis and two to Nocardia. However, 16S rRNA sequencing does not always give clear resolution to distinguish between closely related genera (Girard et al. 2013). To order the actinomycetes, they presented a novel method based on the conserved sequence of genes $S s g \mathrm{~A}$ and $\mathrm{Ssg} \mathrm{B}$ proteins. The wide conserve feature between members of the same genus in amino acid (aa) sequence of the $S s g B$, e.g., only one aa variation was found in between all the $S s g$ B orthologues of identified in Streptomyces, whereas it has low sequence identity as $40-50 \%$ even between genera of closely related morphologically complex actinomycetes, provides concrete data for better resolution in classification systems. Recently, real-time PCR (RT-PCR) technology is being used for the specific detection and quantification of selected PGP genes of actinomycetes. Quantitative real-time PCR of selected PGP genes of actinomycetes revealed the selective up-regulation of indole acetic acid (IAA)-related and siderophore-related genes by Streptomyces sp., CAI-68 and of $\beta$-1,3-glucanase genes (Gopalakrishnan et al. 2015).

\subsection{Utility of Advanced Genomic Approaches in Actinomycetes}

The genomic technologies are promising tools to explore the untapped and novel microbial isolates for characterization in all aspects as we can consider its significance as natural store house of excellent enzymes and bioactive secondary metabolites. Fluorescence-activated cell sorting (FACS) technology is a quick method for separating the cells in a suspension on the basis of fluorescence and cell size. This technology can be performed for isolation of actinomycetes cell from a complex microbial population. Gel MicroDrop technology is an efficient enzymefluorescence technology, basically used for detection of positive clones by capturing of emitted fluorescence from catalytic broke down of biotinylated substrate by specific top articular enzymes present in the positive clone (Short et al. 2003).

Recently, high throughput screening (HTS) technique is considered to be rapid and economical for classifying of any microbial population by enzymatic characterization, but it is extended very little for actinomycetes. HTS consists of drop-based microfluid platform and gives an array data of insoluble substrates specific for the desired enzymes (Chang et al. 2013). Compared with all HTS-based methods, currently the proteomics approach is well accepted in the way of discovering new microbial flora and fauna. Wang et al. (2012a) first reported on Streptomyces sp. products $\alpha$-glucosidase inhibitor miglitol using HTS method. They considered 12 actinomycete strains as to be producers of $\alpha$-glucosidase inhibitors in which strain PW409 showed effective inhibitory and was used for fermentation and separation of bioactive compound using HPLC. In mass spectrometry, two compounds, miglitol and 1-deoxynojirimycin, were identified. The method can be utilized for discovering new $\alpha$-glucosidase inhibitors or identifying from other inhibitory strains.

However, the common PCR methods used in microbial detection, the amplified DNA fragment, is always not prominent in visibility for 
the important microbial species, which are relatively less abundant. Nowadays, two promising and pioneering approaches, preamplification inverse-PCR (PAIPCR) and substrate-induced gene expression screening (SIGEX), are used extensively to overcome this problem in characterization of actinomycetes from metagenomic DNA shuffling in a particular microflora (Kennedy et al. 2010). MALDI-LTQ-Orbitrap is one of the proteomics-based techniques for identifying desired proteins from suspensions and complex matrices. This technique is worked based on the principal of chromatography separations in both media liquid and gas with the coordination of MALDI and ion trap system (Akeroyd et al. 2013). Electrospray ionization mass spectrometry (ESI-MS) is another promising ionization technique that can measure proteins as little as femtomole quantities (Smith et al. 2013). Few in silico techniques, e.g., 3DQSAR, CoMSIA, and CoMFA, are likely to be promising to characterize potent enzymes from database and have the ability to predict superior enzymes and its in silico reaction with substrate and development of microenvironment during reaction (Murumkar et al. 2009).

\subsection{Application of Actinomycetes in Agricultural Crops: Genomic Approach}

\subsubsection{Actinomycetes as Source of Bioactive Compounds}

Actinomycetes specifically Streptomyces are the most fruitful source for all types of bioactive secondary metabolites. Approximately $60 \%$ of the new insecticides and herbicides reported in the past 5 years originate from Streptomyces (Tanaka and Omura 1993; Roshan et al. 2013; Kumar et al. 2014b). It also is estimated that as many as three-quarters of Streptomycetes spp. are able to produce antibiotics (Alexander 1977). Actinomycetes produce a variety of secondary metabolites and have a wide range of uses, including antimicrobial, antifungal, herbicidal, antineoplastic, and plant growthpromoting agents. Gopalakrishnan et al. (2011) reported the potential of selected actinomycetes isolates as biological control of Fusarium wilt and dry root rot diseases in grain legumes. They reported five most promising antagonistic isolates of Streptomyces's species (CAI-24, CAI-121, CAI-127, KAI-32, and KAI-90) and characterized for the production of siderophore, hydrocyanic acid (HCN), protease, cellulase, IAA, etc. These actinomycetes are likely to be the potential organisms for discovery of novel secondary metabolites for various biocontrol applications.

\subsubsection{Actinomycetes as a Source of Nitrogen Fixation}

Generally, population of actinomycetes is largely higher in rhizosphere in comparison of non-rhizosphere soils (Miller et al. 1989, 1990). Root colonization of Streptomyces griseoviridis in SEM studies showed a higher density in the rhizosphere of lettuce than in non-rhizosphere soil (Kortemaa et al. 1994). A similar result was found when interaction of Streptomyces lydicus WYEC 108 and nodules of pea was studied in SEM. S. lydicus was found to be colonized at nodulation sites, and then the vegetative hyphae moved onto root hairs and from the external surface of the root cells to the inside of the root cells, intermittently (Tokala et al. 2002). The PCR-DGGE analysis of DNA from colonized nodules showed the presence of a Streptomyces band in addition to other bands corresponding to the plant and Rhizobium.

Rhizobia with legumes are considered under PGPR genera and play a bigger role in nitrogen fixation. Nitrogen is the most essential nutrient for plant productivity and growth, and it is a vital element for all forms of life. Although $78 \%$ of the atmospheric volume contains dinitrogen they remain unavailable to the plants. Plant growthpromoting actinomycete Frankia has the ability to fix atmospheric nitrogen to ammonia 
(available form for plants) and provide it to plants by symbiotic association with non-leguminous trees and shrubs (Zahran 2001; Ahemad and Kibret 2014). The nitrogenase (nif) genes responsible for nitrogen fixation are found in systems: free living or symbiotic (Reed et al. 2011). The nif genes include structural genes responsible for electron donation, ironmolybdenum cofactor biosynthesis, and involved in activation of the Fe-protein, and regulatory genes responsible for the synthesis and function of the enzyme.

\subsubsection{Molecular Basis of Nitrogen Fixation}

Agrobacterium rhizogenes and Agrobacterium tumefaciens are available for studying downregulation of plant genes by RNAi in some actinorhizal plants (Svistoonoff et al. 2003; Gherbi et al. 2008a, b). In transcriptome analyses, it is found that the common symbiosis (SYM) pathway shared by rhizobium-legume and arbuscular mycorrhizal for nodulation symbiosis is present in Frankia (Gherbi et al. 2008a, b; Markmann et al. 2008; Hocher et al. 2011). For the induction of calcium oscillations in this pathway, a receptor, potassium channels, and nuclear pore proteins are required. A putative calcium/calmodulin-dependent protein kinase (CCaMK) also is present and might thus recognize calcium "actinorhizal signatures" (Singh and Parniske 2012). The similar genes linked to a NOD-specific pathway used by legumes for the nodulation process also is present in Frankia. This overlapping of legume and actinorhizal root nodule symbiosis RNS supports the hypothesis of a common genetic ancestor with a genetic predisposition for nodulation in the nitrogenfixing clade (Soltis et al. 1995).

Because traditional approaches are not yet available for studying Frankia genetics, most work has proceeded through the cloning of genes via heterologous hybridization to genes from other organisms, most notably those involved in nitrogen metabolism. These genes include the cloning and sequencing of nif $\mathrm{H}$ (Normand and Bousquet 1989; Normand et al. 1988), nif D (Twigg et al. 1990; Normand et al. 1992), part of nifK (Twigg et al. 1990), nif $\mathrm{B}$, nif $\mathrm{X}$, nif $W$, and nif $\mathrm{Z}$, open reading frames that correspond to the Azotobacter vinelandii orf 3 and Azorhizobium caulinodans orf 1 (Arigoni et al. 1991). At least 20 nif genes are involved in $\mathrm{N}_{2}$ fixation in the well-characterized Klebsiella pneumoniae, and many of these genes have homologs in other diazotrophs (Dean and Jacobson 1992).

The nitrogenase and associated proteins are highly conserved in prokaryotes. Nitrogenase of Frankia also is $\mathrm{O}_{2}$ labile, requires $\mathrm{Mg}$ ATP and reducing power, and produces $\mathrm{NH}_{4}{ }^{-}$and $\mathrm{H}_{2}$ gas in an ATP-dependent fashion (Benson et al. 1979). There is no alternative $\mathrm{N}_{2}$ fixing systems akin to the vanadium or iron-based nitrogenases reported from Frankia. Because Frankia grow and respire slowly, the delivery of substrates to nitrogenase and the maintenance of a low $\mathrm{O}_{2}$ level in the proximity of nitrogenase are important problems encountered by Frankia strains. The structural genes for the Fe protein and the Mo-Fe protein of nitrogenase are encoded by the nif $\mathrm{H}$ and the nif $\mathrm{D}$ and nifK genes, respectively. Hybridization results have indicated that nifHDK in some Frankia strains are clustered on the chromosome (Mullin and An 1990), five genes about 4 kbp downstream from nifHDK have been sequenced, four of which belong to a single operon consisting of at least orf 3, orf 1 , nif $\mathrm{W}$, and nifZ; nif $\mathrm{B}$ is located immediately downstream from nifZ and may be transcribed as part of another operon. The nif $\mathrm{B}$, nif $\mathrm{W}$, and nifZ are all involved in FeMocofactor biosynthesis (Dean and Jacobson 1992). Nucleotide and amino acid sequence analyses of nif $\mathrm{H}$, nif $\mathrm{D}$, and other nif genes confirm the similarity of Frankia nitrogenase with the classical Mo-Fe protein based systems (Normand and Bousquet 1989; Normand et al. 1988; Simonet et al. 1986). The most common genes present in bacteria for symbiosis and $\mathrm{N}_{2}$ fixation is as follows (Table 16.1). 
Table 16.1 Most common genes present in bacteria and actinomycetes involved in symbiosis and nitrogen fixation

\begin{tabular}{|c|c|}
\hline Genes & Function of gene product \\
\hline \multicolumn{2}{|c|}{ Nodulation genes } \\
\hline $\operatorname{nodA}$ & Acyltransferase \\
\hline $\operatorname{nod} \mathrm{B}$ & Chitooligosaccharide deacetylase \\
\hline $\operatorname{nod} \mathrm{C}$ & N-acetylglucosaminyltransferase \\
\hline $\operatorname{nod} \mathrm{D}$ & $\begin{array}{l}\text { Transcriptional regulator of common } \\
\text { nod genes }\end{array}$ \\
\hline nodIJ & Nod factors transport \\
\hline nodPQ & Synthesis of Nod factors substituent \\
\hline $\operatorname{nodX}$ & Synthesis of Nod factors substituent \\
\hline$n o f \mathrm{EF}$ & Synthesis of Nod factors substituent \\
\hline $\begin{array}{l}\text { Other nod } \\
\text { genes }\end{array}$ & $\begin{array}{l}\text { Several functions in synthesis of Nod } \\
\text { factors }\end{array}$ \\
\hline nol genes & $\begin{array}{l}\text { Several functions in synthesis of Nod } \\
\text { factors substituent and secretion }\end{array}$ \\
\hline$N O E$ genes & Synthesis of Nod factors substituent \\
\hline \multicolumn{2}{|c|}{ Nitrogen fixation genes } \\
\hline nif $\mathrm{HDK}$ & Nitrogenase \\
\hline nifA & Transcriptional regulator \\
\hline nif $\mathrm{BEN}$ & Biosynthesis of the Fe-Mo cofactor \\
\hline $\begin{array}{l}\text { nif } \mathrm{B}, \text { nif } \mathrm{W}, \\
\text { and nif } \mathrm{Z}\end{array}$ & Fe-Mo cofactor biosynthesis \\
\hline fix ABCX & Electron transport chain to nitrogenase \\
\hline fixNOPQ & Cytochrome oxidase \\
\hline$f i x \mathrm{LJ}$ & Transcriptional regulators \\
\hline$f i x \mathrm{~K}$ & Transcriptional regulator \\
\hline fixGHIS & Copper uptake and metabolism \\
\hline$f d x \mathrm{~N}$ & Ferredoxin \\
\hline \multicolumn{2}{|l|}{ Other genes } \\
\hline exo & Exopolysaccharide production \\
\hline hup & Hydrogen uptake \\
\hline$g \ln$ & Glutamine synthase \\
\hline$d c t$ & Dicarboxylate transport \\
\hline nfe & $\begin{array}{l}\text { Nodulation efficiency and } \\
\text { competitiveness }\end{array}$ \\
\hline$n d v$ & $\beta-1,2$ glucans synthesis \\
\hline lps & Lipopolysaccharide production \\
\hline
\end{tabular}

Source: Laranjoa et al. (2014)

\subsection{Characterization of Actinomycetes Through Whole Genome Sequencing}

Advancement of WGS has unchained the understanding of whole biochemical and molecular potentiality prevailing even in those microbes incompetent in laboratory culture from a composite environment. The WGS of microbes revealed the chemistry of the cryptic clusters of biosynthetic-related genes that are sometimes present but hidden, because those are not well recognized for any secondary metabolites synthesis (Fraser et al. 2002). Currently, six genera of actinomycetes, namely Frankia, Arthrobacter, Corynebacterium, Mycobacterium, Rhodococcus and Streptomyces, have enough information on whole genome sequences to extemporize the basic analysis of potential secondary metabolite and gene diversity (James and William 2013).

\subsubsection{Gene Cluster Diversity Within Actinomycete Groups}

The genomes of actinomycetes revealed that they have gene clusters for a high number of natural products, although a lot of these are very complex to tie to products in the laboratory. The evaluations of these gene clusters are more difficult, because the existed domains of the most common biosynthetic machinery, non-ribosomal peptide synthetases (NRPSs) and polyketide synthases (PKSs), are repeated and highly similar. It is predictable that for being diverse lifestyles that habitats use secondary metabolites differently by different genera of actinomycetes.

In many genera, it was found that the siderophores are the most conserved secondary metabolite clusters, whether they are NRPSindependent or NRPS products. The study of Doroghazi and Metcalf (2013) showed that genomes 41 of 102 common actinomycetes contain at minimum one gene cluster for siderophore biosynthesis, which is NRPS-independent (aerobactin-like), whereas 31 genomes of 34 actinomycetes in the group of Nocardia, Mycobacterium, and Corynebacterium do not have this class of siderophores, but except Corynebacterium kroppenstedtii all contain the gene cluster for mycolic acid. In general, the more pathogenic genus Mycobacterium and Corynebacterium contain gene clusters for higher proportions of conserved secondary metabolite, whereas in Streptomyces and Rhodococcus, the 
essentially saprophytic genera are less conserved. This may be due to pathogens that are inhabited in the increased homogeneity of environments compared with free-living bacteria. The pattern of host-association in Frankia is different where no overlap secondary metabolic capabilities are present. It is assumed that over the evolutionary period, the location of the gene clusters of natural product will change through horizontal gene transfer and it would make change in the genomes and phylogenetic trees because of genome rearrangements (Fischbach et al. 2008; Osbourn 2010).

Based on genomic data only, Streptomyces spp. are the most important actinobacterial groups for secondary metabolites (Table 16.2). Streptomyces consists of large numbers of biosynthetic gene clusters related to secondary metabolite with a large variety of classes. The common classes of PKS and NRPS are present in the majority of the Streptomyces, followed by terpenoids, aerobactinlike non-NRPS siderophores, and lanthipeptides. Most of the genomes contain the genes for butyrolactone biosynthesis. All Streptomyces spp. contain the genes responsible for the biosynthesis of the aerobactin-like siderophore desferrioxamine. Except for S. griseus, all Streptomyces contain gene cluster for the spore pigment type II PKS, whereas $S$. griseus contains type III PKS for a different spore pigment (Ohnishi et al. 2008). Only half of the strains, including $S$. griseus and S. coelicolor A3 (2), contain the gene cluster lanthipeptide $\operatorname{SapB}$ that is required for aerial mycelia formation on rich media (Kodani et al. 2004). This genus has very low amount of overlap gene clusters of PKS and

Table 16.2 Recent genome publications for Streptomyces species

\begin{tabular}{|c|c|c|}
\hline Species and strain & Motivation for sequencing & References \\
\hline S. albulus CCRC 11814 & Produces $\varepsilon$-poly-L-lysine antibiotic & Dodd et al. (2013) \\
\hline S. albus J1074 & $\begin{array}{l}\text { Widely used host for heterologous expression of bioactive } \\
\text { natural products; Small genome }\end{array}$ & $\begin{array}{l}\text { Zaburannyi } \\
\text { et al. (2014) }\end{array}$ \\
\hline S. albulus PD-1 & $\begin{array}{l}\text { Produces } \varepsilon \text {-poly-L-lysine and poly-L-diaminopropionic acid } \\
\text { antibiotics }\end{array}$ & Xu et al. (2014b) \\
\hline $\begin{array}{l}\text { S. bottropensis ATCC } \\
25435\end{array}$ & Produces bottromycin antibiotics & Zhang et al. (2013) \\
\hline S. collinus Tu 365 & Produces elfamycin-family antibiotic kirromycin & Rückert et al. (2013) \\
\hline S. exfoliatus DSMZ 41693 & Degrades poly3-hydroxyalkanoate & $\begin{array}{l}\text { Martínez } \\
\text { et al. }(2014)\end{array}$ \\
\hline S. fulvissimus DSM 40593 & Produces ionophore antibiotic valinomycin & $\begin{array}{l}\text { Myronovskyi } \\
\text { et al. (2013) }\end{array}$ \\
\hline S. gancidicus BKS 13-15 & Not known & Kumar et al. (2013) \\
\hline S. mobaraensis DSM 40847 & Industrial producer of transglutaminase & Yang et al. (2013) \\
\hline S. niveus NCIMB 11891 & Produces novobiocin, an aminocoumarin antibiotic & $\begin{array}{l}\text { Flinspach } \\
\text { et al. }(2014)\end{array}$ \\
\hline $\begin{array}{l}\text { S. rapamycinicus NRRL } \\
5491\end{array}$ & Produces immunosuppressant drug rapamycin & $\begin{array}{l}\text { Baranasic } \\
\text { et al. }(2013)\end{array}$ \\
\hline S. rimosus ATCC 10970 & Oxytetracycline & Pethick et al. (2013) \\
\hline $\begin{array}{l}\text { S. roseochromogenes subsp. } \\
\text { oscitans DS } 12.976\end{array}$ & Produces clorobiocin, an aminocoumarin antibiotic & Rückert et al. (2014) \\
\hline Streptomyces sp. $\mathrm{Mg} 1$ & $\begin{array}{l}\text { Causes lysis and degradation of Bacillus subtilis cells and } \\
\text { colonies. Sequenced using the PacBio platform }\end{array}$ & Hoefler et al. (2013) \\
\hline Streptomyces sp. PRh5 & An endophyte isolated from wild rice root & Yang et al. (2014) \\
\hline S. violaceusniger SPC6 & Tolerant to multiple stresses. Small genome & Chen et al. (2013) \\
\hline S. viridochromogenes Tu57 & Produces oligosaccharide antibiotic avilamycin & Grüning et al. (2013) \\
\hline S. viridosporus T7A & Produces oligosaccharide antibiotic avilamycin & Davis et al. (2013) \\
\hline
\end{tabular}

Source: Harrison and Studholme (2014) 
NRPS. Although a large amount of polyketides and non-ribosomal peptides has been discovered already from Streptomyces, there are only a few reports for terpenoids in streptomycetes. However, a number of terpene synthases has been discovered in genomes of Streptomyces sp., suggesting that a large diverge group of terpenoids has remained to be discovered in members of this genus.

\subsection{Genomics and Genetic Information of Streptomyces}

With the goal of discovering novel bioactive compounds, the huge genomic data of Streptomyces and other related species has led to cheap genome sequencing techniques (Liu et al. 2013). However, productive "genome mining" is possible only when the gene clusters clone and express in any heterologous host or to force expression by genetic modification (Gomez-Escribano and Bibb 2014). Therefore, unavoidably there will be a lag between the initial state of genome characterization by sequencing and harder to depict the novel useful products by biochemical investigations. Streptomyces PRh5, an endophyte of wild rice, produces nigericin, an antibiotic active antagonized to mycobacteria is recently discovered (Yang et al. 2014). Genetic information of Streptomyces species and few other actinomycetes genera are as follows:

Streptomyces sp. strain CT34: total assembly size of the genome of Streptomyces sp. strain CT34 is 8,066,430 bp, with coverage of $99.85 \%$. The genome contains an average GC content of $\sim 71.39 \%$ with 7781 protein coding genes of an average length of $875 \mathrm{bp}$. The predicted total gene length is about $6,809,991 \mathrm{bp}$, which makes up $84.42 \%$ of the genome. The analysis of genome data revealed that it comprises 30 gene clusters for secondary metabolites biosynthesis, including four for terpene biosynthesis, three of each for siderophores, PKSs (2T2-PKSs, 1T3-PKS), NRPSs, bacteriocins, and butyrolactones; two for lantipeptides, one of each for mixed lantipeptide/ PKS (T1-PKS), mixed PKS (T4-PKS)/PKS (T1-PKS), mixed oligosaccharide/terpene, mixed non-ribosomal peptide synthetase (NRPS)/ polyketide synthase (T1-PKS), and ectoine; and four unspecified clusters. A putative gene cluster of 12,108 bp comprises ten ORFs encoding proteins for catalytic activity and auxiliary functions and one ORF for the biosynthesis of prepeptide related to new linaridin RiPP is found to be present in the genome (Zhai et al. 2015).

Streptomyces sp. strain TOR3209: The draft genome sequence of Streptomyces sp. TOR3209 is 8,066,796-bp long with an average GC content of $72.59 \%$. It comprises 4 rRNA genes, 73 tRNA genes, and 7564 protein encoding genes with an average length of $937 \mathrm{bp}$. The sequence annotation revealed that among all of the genes, 187 genes are associated with transport, biosynthesis, and catabolism of secondary metabolites and 322 genes of unknown function. It is found that among the protein-encoding genes, several genes are involved with the regulation mechanism of rhizosphere microecology, because they take a part in the production of flavonol, flavone, hormones, terpenoid, quinone, antibiotics, and other active substances. In addition, 29 degradation pathways of toxic substances are present in TOR3209 genome. These distinguished features are not present in other microorganisms. The degradation pathways for toxic substances that are difficult to degrade include naphthalene, carbazole, fluorene, anthracene, xylene toluene, trinitrotoluene, atrazine, and ethylbenzene. These pathways may help to resolve toxic substances around crop roots. The genomic information of Streptomyces sp. strain TOR3209 has great significance to the research field oriented with the regulation mechanism of rhizosphere microecology (Hu et al. 2012).

Streptomyces sp. strain AW19M42: The total size of the genome is $8,008,851 \mathrm{bp}$ and has a GC content of $70.57 \%$, similar to that of other sequenced Streptomyces isolates. A total of 7727 coding DNA sequences are predicted. In addition, 62 tRNAs and 8 copies of the rRNA operons are identified in the genome of Streptomyces sp. strain AW19M42 (Bjerga et al. 2014).

Streptomyces albus strain J1074: The total genome size of S. albus strain J1074 is $6,841,649$ bp. It is one of the smallest 
Streptomyces genomes along with Streptomyces cattleya (Zaburannyi et al. 2014). However, the strain contains a mega plasmid pSCAT of $1,809,491 \mathrm{bp}$. Analysis of chromosomal genes revealed that $S$. albus contains highest known GC content $\sim 73.3 \%$ within the Streptomycetes. It is found that $S$. albus have a tendency to reduce the number of orthologous groups of genes. Unlike those of other Streptomycetes genomes, it has the single chromosome includes 66 tRNA genes (41 species) and 7 rRNA operons (16S-23S-5S). The presence of seven rRNA operons may help the strain for its exceptionally fast growth rate and versatility (Klappenbach et al. 2000).

Streptomyces acidiscabies strain 84-104: The size of the draft genome sequence of $S$. acidiscabies is approximately $11,005,945 \mathrm{bp}$ in length (Huguet-Tapia and Loria 2012). The genome encodes 10,070 putative proteins. Reciprocal BLAST analysis with other Streptomyces genomes is noted that $S$. acidiscabies 84-104 contains 75 tRNA genes and shares 3006 orthologs with $S$. scabies, $S$. coelicolor, S. griseous, S. avermitilis, and S. bingchenggensis. S. acidiscabies and S. scabies shares 357 orthologs, including many of which are in asyntenic (HuguetTapia et al. 2011).

Streptomyces albus strain NBRC 13014 T: The total size of the assembly of $S$. albus NBRC 13014T genome is 7,594,701 bp, with a GC content of $72.7 \%$. The genome contains at least one type-II PKS, two NRPS, two hybrid PKS/NRPS, and four type-I PKS gene clusters (Komaki et al. 2015). The type-II PKS gene cluster is required for synthesize of xantholipinlike compounds, because its CLF and KS showed $78 \%$ and $89 \%$ aa sequence identities to XanE and XanF, respectively (Zhang et al. 2012).

Streptomyces auratus strain AGR0001: The genome of $S$. auratus strain AGR0001 contains a linear chromosome of 7,885,420 bp, with average GC content of $71.45 \%$. The chromosome of S. auratus strain AGR0001 comprises 66 tRNA genes, 8 rRNA operons, and 7102 protein-coding genes that encode at least 3935 proteins with assigned putative functions. At least 33 putative gene clusters were identified for the biosynthesis of PKS, NRPS, or terpene in the genome of S. auratus strain AGR0001 (Han et al. 2012).

$S$ coelicolor strain A3(2): S. coelicolor strain A3(2), a producer of most natural antibiotics, is a representative of the group of soil-dwelling, filamentous bacteria. The linear chromosome of this organism is approximately 8,667,507-bp long, containing the largest number of genes. The genome contains a total number of 7825 predicted protein genes, including more than 20 clusters that are identified as responsible for coding of predicted known secondary metabolites (Bentley et al. 2002).

Streptomyces globisporus strain C-1027: The analysis of draft sequence of whole genome of S. globisporus C-1027 revealed that the chromosome is 7,693,617-bp long with GC content of $71.63 \%$. The chromosome contains 56 tRNA genes, 5 rRNA operons, and at least 7231 putative protein CDSs account for $88.22 \%$ of the genome. A number of clusters related to biosynthesis of varied secondary metabolites, including putative PKS genes, NRPS genes, NRPS-PKS hybrid genes, terpene cyclase genes, and lantibiotic biosynthesis, are found to be present in the genome of S. globisporus strain C-1027. The complete genome sequence of S. globisporus C-1027 will aid with understanding the biosynthesis-regulatory mechanisms of C-1027 and identifying new natural bioactive compounds by uncovering hidden metabolic pathways (Wang et al. 2012b).

S. griseus strain IFO 13350: The complete genome sequence of $S$. griseus is of $8,545,929$ bp in length with no plasmids. The analysis of $S$. griseus chromosome showed that it contains at least 7138 ORFs; of them a total of 4464 ORFs are associated with known or putative functions, and the remaining 2674 ORFs are hypothetical proteins. The chromosome contains 66 tRNA genes (42 species) and 6 rRNA operons (16S-23S-5S). The average GC content of the chromosome is $72.2 \%$, but the $\sim 300-\mathrm{kb}$ regions at both ends (including the $133-\mathrm{kb}$ TIR sequence) contained lower GC content. The replication origin oriC is found to be located at positions of 4,324,631-4,325,203 bp. Nineteen DnaA box-like sequences are predicted to be present 
in the middle of the chromosome (52 kb away from the center toward the right end) (Ohnishi et al. 2008).

Streptomyces zinciresistens strain K42: The initial genome sequence data of $S$. zinciresistens strain K42 showed that it comprises 8,228,741 bp with high GC content of $72.46 \%$. It contained a single plasmid of $30,979 \mathrm{bp}$. The $5 \mathrm{~S}, 16 \mathrm{~S}$, and probably multiple copies of 23SrRNAs, 7307 protein-coding sequences (CDSs), and 69 tRNA genes are annotated. The genome has 2019 proteins with orthologs in $S$. coelicolor, $S$. avermitilis, $S$. griseus, and $S$. scabiei. It has 2520 hypothetical proteins, which may give the high degree genome specificity of strain K42. A total of 61 diverse secondary metabolic genes, of them 31 genes predicted to be involved in biosynthesis of antibiotics could be identified in the genome of K42 (Lin et al. 2011).

Kocuria rhizophila strain DC2201: K. rhizophila, a divergent bacterial group of soil actinomycete belongs to the suborder Micrococcineae. Until now, a limited amount of genomic information has been available for $K$. rhizophila. Annotation of the whole genome sequence of $K$. rhizophila DC2201 (NBRC 103217) revealed that it contains a single circular chromosome of 2,697,540 bp with high GC content of $\sim 71.16 \%$. It has 2357 predicted proteincoding genes; most of those $(87.7 \%)$ are orthologous to actinobacterial proteins with fairly good conservation of synteny with related actinobacterial genomes. In contrast, the genome seems to encode very few numbers of proteins required for lateral gene transfer, transcriptional regulation, and secondary metabolism (one each of NRPS and type III PKS), indicating the small genome size. The presence of a large number of genes related with membrane transport, especially drug efflux pumps and amino acid transporters, and of possible metabolic pathways for the transformation of phenolic compounds generated after degradation of plant materials, may contribute to the tolerance in various organic compounds and to organism's utilization of root exudates (Takarada et al. 2008).

Amycolatopsis orientalis HCCB10007: The complete genome of A. orientalis HCCB10007 contains an 8,948,591-bp circular chromosome and a 33,499-bp dissociated plasmid. In total, 8121 protein-coding sequences are predicted to be present in the genome. In addition, 26 gene clusters related to secondary metabolism, including the 64-kb vancomycin cluster encoded a halogenase, a methyltransferase, and two glycosyltransferases (Xu et al. 2014a).

Rhodococcus imtechensis RKJ300: The genome of $R$. imtechensis RKJ300 is $8,231,486$ bp with GC content of $67.22 \%$. The genome comprises of 8059 predicted coding regions (CDSs), 49 tRNAs, and 5 rRNA genes (Vikram et al. 2012).

\subsection{Conclusion}

Researchers have great interest in the selection of actinomycetes, because they are importance in sustainable agriculture and are able to antagonize most deleterious phytopathogens. A large number of bioactive compounds have been isolated from different actinomycetes, mostly from Streptomyces spp. Different molecular approaches and bioinformatics tools are dynamic for discovering and characterizing the vast actinomycetes diversity. Furthermore, WGS can unzip the chemistry of the cryptic clusters of biosynthetic-related genes that are sometimes present but crypted, because those are not well acknowledged for synthesizing any antimicrobial compounds. In near future, those bioactive products synthesized-related genes may arise as the key of antagonism of major phytopathogens as well as PGP in crops.

\section{References}

Ahemad M, Kibret M (2014) Mechanisms and applications of plant growth-promoting rhizobacteria: current perspective. J King Saude Univ Sci 26:1-20

Akeroyd M, Olsthoorn M, Gerritsma J (2013) Searching for microbial protein over-expression in a complex matrix using automated high throughput MS-based proteomics tools. J Biotechnol 164:112-120

Alexander M (1977) Introduction to soil microbiology. Krieger Publishing Company, Malabar, p 467 
Arigoni F, Kaminski PA, Hennecke H, Elmerich C (1991) Nucleotide sequence of the fix $\mathrm{ABC}$ region of Azorhizobium caulinodans ORS571: similarity of the fix $\mathrm{B}$ product with eukaryotic flavoproteins, characterization of fixX, and identification of nifW. Mol Gen Genet 225:514-520

Baranasic D, Gacesa R, Starcevic A, Zucko J, Blazic M, Horvat M, Gjuračić K, Fujs S, Hranueli D, Kosec G, Cullum J, Petković H (2013) Draft genome sequence of Streptomyces rapamycinicus strain NRRL 5491, the producer of the immunosuppressant rapamycin. Genome Announc 1:e00581-13

Benson DR, Arp DJ, Bums RH (1979) Cell-free nitrogenase and hydrogenase from actinorhizal root nodules. Science 205:688-689

Bentley SD, Chater KF, Cerdeño-Tárraga AM, Challis GL, Thomson NR, James KD, Harris DE, Quail MA, Kieser H, Harper D, Bateman A, Brown S, Chandra G, Chen CW, Collins M, Cronin A, Fraser A, Goble A, Hidalgo J, Hornsby $\mathrm{T}$, Howarth $\mathrm{S}$, Huang $\mathrm{CH}$, Kieser T, Larke L, Murphy L, Oliver K, O’Neil S, Rabbinowitsch E, Rajandream MA, Rutherford K, Rutter S, Seeger K, Saunders D, Sharp S, Squares R, Squares S, Taylor K, Warren T, Wietzorrek A, Woodward J, Barrell BG, Parkhill J, Hopwood DA (2002) Complete genome sequence of the model actinomycetes Streptomyces coelicolorA3(2). Nature 417:141-147

Bjerga GEK, Hjerde H, De Santi C, Williamson AK, Smalås AO, Willassen NP, Altermark B (2014) High quality draft genome sequence of Streptomyces sp. strain AW19M42 isolated from a sea squirt in Northern Norway. St Genome Sci 9:676-686

Chang C, Sustarich J, Bharadwaj R, Chandrasekaran A, Adams PD, Singh AK (2013) Droplet-based microfluidic platform for heterogeneous enzymatic assays. Lab Chip 13:1817-1822

Chen X, Zhang B, Zhang W, Wu X, Zhang M, Chen T, Zhanga M, Chena T, Liua G, Dysonb P (2013) Genome sequence of Streptomyces violaceusniger strain SPC6, a halotolerant streptomycete that exhibits rapid growth and development. Genome Announc 1:00494-13

Davis JR, Goodwin L, Teshima H, Detter C, Tapia R, Han C, Huntemann M, Wei CL, Han J, Chen A, Kyrpides K, Mavrommatis N, Szeto E, Markowitz V, Ivanova N, Mikhailova N, Ovchinnikova G, Pagani I, Pati A, Woyke T, Pitluck S, Peters L, Nolan ML, Jason K, Sello J (2013) Genome sequence of Streptomyces viridosporus strain T7A ATCC 39115, a lignindegrading actinomycete. Genome Announc 1: e00416-13

Dean DR, Jacobson MR (1992) Biochemical genetics of nitrogenase. In: Stacey G, Burris RH, Evans HJ (eds) Biological nitrogen fixation. Chapman and Hall, New York, pp 763-834

Dodd A, Swanevelder D, Featherston J, Rumbold K (2013) Draft Genome sequence of Streptomyces albulus strain CCRC 11814, an $\varepsilon$-poly-L-lysine-producing actinomycete. Genome Announc 1:e00696-13
Doroghazi JR, Metcalf WW (2013) Comparative genomics of actinomycetes with a focus on natural product biosynthetic genes. BMC Genomics 14:611

Fischbach MA, Walsh CT, Clardy J (2008) The evolution of gene collectives: how natural selection drives chemical innovation. Proc Natl Acad Sci U S A 105:4601-4608

Flinspach K, Rückert C, Kalinowski J, Heide L, Apel AK (2014) Draft genome sequence of Streptomyces niveus NCIMB 11891, producer of the aminocoumarin antibiotic novobiocin. Genome Announc 2:e01146-13

Fraser CM, Eisen JA, Nelson KE, Paulsen IT, Salzberg SL (2002) The value of complete microbial genome sequencing (you get what you pay for). J Bacteriol 23:6403-6405

Gherbi H, Markmann K, Svistoonoff S, Estevan J, Autran D, Giczey G, Auguy F, Péret B, Laplaze L, Franche C, Parniske M, Bogusz D (2008a) SymRK defines a common genetic basis for plant root endosymbiosis with arbuscular mycorrhiza fungi, rhizobia and Frankia bacteria. Proc Natl Acad Sci U S A 105:4928-4932

Gherbi H, Nambiar-Veetil M, Zhong C, Félix J, Autran D, Girardin R, Vaissayre V, Auguy F, Bogusz D, Franche C (2008b) Post-transcriptional gene silencing in the root system of the actinorhizal tree Allocasuarina verticillata. Mol Plant Microbe Interact 21:518-524

Girard G, Traag BA, Sangal V, Mascini N, Hoskisson PA, Goodfellow M, van Wezel GP (2013) A novel taxonomic marker that discriminates between morphologically complex actinomycetes. Open Biol 10:130073

Gomez-Escribano JP, Bibb MJ (2014) Heterologous expression of natural product biosynthetic gene clusters in Streptomyces coelicolor: from genome mining to manipulation of biosynthetic pathways. J Ind Microbiol Biotechnol 41:425-431

Gopalakrishnan S, Pande S, Sharma M, Humayun P, Kiran BK, Sandeep D, Vidya MS, Deepthi K, Rupela O (2011) Evaluation of actinomycete isolates obtained from herbal vermicompost for the biological control of Fusarium wilt of chickpea. Crop Prot 30:1070-1078

Gopalakrishnan S, Srinivas V, Alekhya G, Prakash B, Kudapa H, Rathore A, Varshney RK (2015) The extent of grain yield and plant growth enhancement by plant growth-promoting broad-spectrum Streptomyces sp. in chickpea. Springerplus 4:31

Grüning BA, Erxleben A, Hähnlein A, Günther S (2013) Draft genome sequence of Streptomyces viridochromogenes strain Tu57, producer of avilamycin. Genome Announc 1:e00384-13

Han X, Li M, Ding Z, Zhao J, Ji K, Wen M, Lu T (2012) Genome sequence of Streptomyces auratus strain AGR0001, a phoslactomycin-producing actinomycete. J Bacteriol 194:5472-5473

Harrison J, Studholme DJ (2014) Recently published Streptomyces genome sequences. Microb Biotechnol 7:373-380

Heuer H, Krsek M, Baker P, Smalla K, Wellington EMH (1997) Analysis of actinomycete communities by 
specific amplification of genes encoding 16S rRNA and gel-electrophoretic separation in denaturing gradients. Appl Environ Microbiol 63:3233-3241

Hocher V, Alloisio N, Auguy F, Fournier P, Doumas P, Pujic P, Gherbi H, Queiroux C, Da Silva C, Wincker P, Normand P, Bogusz D (2011) Transcriptomics of actinorhizal symbioses reveals homologs of the whole common symbiotic signalling cascade. Plant Physiol 156:700-711

Hoefler BC, Konganti K, Straight PDP (2013) De novo assembly of the Streptomyces sp. strain $\mathrm{Mg} 1$ genome using PacBio single-molecule sequencing. Genome Announc 1:1-2

Hu D, Li X, Chang Y, He H, Zhang C, Jia N, Li H, Wang Z (2012) Genome sequence of Streptomyces sp. Strain TOR3209, a rhizosphere microecology regulator isolated from tomato rhizosphere. $\mathrm{J}$ Bacteriol 194:1627

Huguet-Tapia JC, Loria R (2012) Draft genome sequence of Streptomyces acidiscabies 84-104, an emergent plant pathogen. J Bacteriol 194:1847

Huguet-Tapia JC, Badger JH, Loria R, Pettis GS (2011) Streptomyces turgidiscabies Car8 contains a modular pathogenicity island that shares virulence genes with other actinobacterial plant pathogens. Plasmid 65:118-124

Intra B, Mungsuntisuk I, Nihira T, Igarashi Y, Panbangred W (2011) Identification of actinomycetes from plant rhizospheric soils with inhibitory activity against Colletotrichum spp., the causative agent of anthracnose disease. BMC Res Notes 4:98

James RD, William WM (2013) Comparative genomics of actinomycetes with a focus on natural product biosynthetic genes. BMC Genomics 14:611

Kennedy J, Flemer B, Jackson SA (2010) Marine metagenomics: new tools for the study and exploitation of marine microbial metabolism. Mar Drugs 8:608-628

Klappenbach JA, Dunbar JM, Schmidt TM (2000) rRNA operon copy number reflects ecological strategies of bacteria. Appl Environ Microbiol 66:1328-1333

Kodani S, Hudson M, Durrant M, Buttner M, Nodwell J, Willey J (2004) The SapB morphogen is a lantibioticlike peptide derived from the product of the developmental gene ramS in Streptomyces coelicolor. Proc Natl Acad Sci U S A 101:11448-11453

Komaki H, Ichikawa N, Oguchi A, Hamada M, Tamura T, Fujitab N (2015) Draft genome sequence of Streptomyces albus strain NBRC 13014T, the type species of the genus Streptomyces. Genome Announc 3:1e01527-14

Kortemaa H, Rita H, Haahtela K, Smolander A (1994) Root colonization ability of antagonistic Streptomyces griseoviridis. Plant Soil 163:77-83

Kumar S, Kaur N, Singh NK, Raghava GPS, Mayilraja S (2013) Draft genome sequence of Streptomyces gancidicus strain BKS 13-15. Genome Announc 1:2e00150-13
Kumar R, Biswas K, Soalnki V, Kumar P, Tarafdar A (2014a) Actinomycetes: potential bioresource for human welfare: a review. Res J Environ Sci 2:5-16

Kumar R, Biswas K, Tarafdar A, Soalnki V, Kumar P, Shankar P (2014b) Recent advancement in biotechnological and molecular approaches of actinomycetes: a review. Bull Environ Pharmacol Life Sci 3:189-192

Laranjoa M, Alexandrea A, Oliveiraa S (2014) Legume growth-promoting rhizobia: an overview on the Mesorhizobium genus. Microbiol Res 169:2-17

Lin Y, Hao X, Johnstone L, Miller SJ, Baltrus DA, Rensing C, Wei G (2011) Draft genome of Streptomyces zinciresistens $\mathrm{K} 42$, a novel metal-resistant species isolated from copper-zinc mine tailings. J Bacteriol 193:6408-6409

Liu G, Chater KF, Chandra G, Niu G, Tan H (2013) Molecular regulation of antibiotic biosynthesis in Streptomyces. Microbiol Mol Biol Rev 77:112-143

Markmann K, Giczey G, Parniske M (2008) Functional adaptation of a plant receptor-kinase paved the way for the evolution of intracellular root symbioses with bacteria. PLoS Biol 6:e68

Martínez V, Hormigo D, del Cerro C, Gómez de Santos P, García-Hidalgo J, Arroyo M, Prieto A, García JL, de la Mata I (2014) Genome sequence of Streptomyces exfoliatus DSMZ 41693, a source of poly (3-hydroxyalkanoate)-degrading enzymes. Genome Announc 2:e01272-13

Miller JJ, Liljeroth E, Henken G, van Veen JA (1989) Fluctuations in the fluorescent pseudomonad and actinomycetes populations of rhizosphere and rhizoplane during the growth of spring wheat. Can J Microbiol 36:254-258

Miller JJ, Liljeroth E, Willemsen-de Klein MJEIM, van Veen JA (1990) The dynamics of actinomycetes and fluorescent pseudomonads in wheat rhizoplane and rhizosphere. Symbiosis 9:389-391

Mullin BC, An CS (1990) The molecular genetics of Frankia. In: Schwintzer CR, Tjepkema JD (eds) The biology of Frankia and actinorhizal plants. Academic, New York, pp 195-214

Murumkar PR, Gupta SD, Zambre VP, Giridhar R, Yadav MR (2009) Development of predictive 3DQSARCoMFA and CoMSIA models for $\beta$-aminohydroxamic acid-derived tumour necrosis factor- $\alpha$ converting enzyme inhibitors. Chem Biol Drug Des 73:97-107

Muyzer G (1999) DGGE/TGGE: a method for identifying genes from natural ecosystems. Curr Open Microbiol 2:317-322

Myers RM, Fischer SG, Lerman LS, Maniatis T (1985) Nearly all single base substitutions in DNA fragments joint to a GC-clamp can be detected by denaturing gradient gel electrophoresis. Nucleic Acids Res 13:3131-3145

Myronovskyi M, Tokovenko B, Manderscheid N, Petzke L, Luzhetskyy A (2013) Complete genome sequence of Streptomyces fulvissimus. J Biotechnol 168:117-118 
Normand P, Bousquet J (1989) Phylogeny of nitrogenase sequences in Frankia and other nitrogen-fixing microorganisms. J Mol Evol 29:436-447

Normand P, Simonet P, Bardin R (1988) Conservation of nif sequences in Frankia. Mol Gen Genet 213:238-246

Normand P, Gouy M, Cournoyer B, Simonet P (1992) Nucleotide sequence of nifD from Frankia alni strain ArI3: phylogenetic inferences. Mol Biol Evol 9:495-506

O’Donnell AG, Embley TM, Goodfellow M (1993) Future of bacterial systematics. In: Goodfellow M, O'Donnell AG (eds) Handbook of new bacterial systematics. Academic, London, pp 513-524

Ohnishi Y, Ishikawa J, Hara H, Suzuki H, Ikenoya M, Ikeda H, Yamashita A, Hattori M, Horinouchi S (2008) Genome sequence of the streptomycinproducing microorganism Streptomyces griseus IFO 13350. J Bacteriol 190:4050-4060

Osbourn A (2010) Secondary metabolic gene clusters: evolutionary toolkits for chemical innovation. Trends Genet 26:449-457

Pethick FE, Macfadyen AC, Tang Z, Sangal V, Liu T-T, Chu J, Kosec G, Petkovic H, Guo M, Kirby R, Hoskisson PA, Herron PR, Huntera IS (2013) Draft genome sequence of the oxytetracycline-producing bacterium Streptomyces rimosus ATCC 10970. Genome Announc 1:e00063-13

Reed SC, Cleveland CC, Townsend AR (2011) Functional ecology of free-living nitrogen fixation: a contemporary perspective. Ann Rev Ecol Evol Syst 42:489-512

Riesner D, Steger G, Zimmat R, Owens RA, Wagenhofer M, Hillen W, Vollbach S, Henco K (1989) Temperature-gradient gel electrophoresis of nucleic acids: analysis of conformational transitions, sequence variations, and protein-nucleic acid interactions. Electrophoresis 10:377-389

Roshan K, Tarafdar A, Saurav K, Ali S, Lone SA, Pattnaik S, Tyagi A, Biswas K, Mir ZA (2013) Isolation and screening of bioactive compound from actinomycetes isolated from salt pan of Marakanam district of the state Tamil Nadu, India. Elixir Bio Technol 61:16826-16831

Rückert C, Szczepanowski R, Albersmeier A, Goesmann A, Iftime D, Musiol EM, Blin K, Wohlleben W, Pühler A, Kalinowski J, Weber T (2013) Complete genome sequence of the kirromycin producer Streptomyces collinus Tü 365 consisting of a linear chromosome and two linear plasmids. J Biotechnol 168:739-740

Rückert C, Kalinowski J, Heide L, Apel AK (2014) Draft genome sequence of Streptomyces roseochromogenes subsp. oscitans DS 12.976, producer of the aminocoumarin antibiotic clorobiocin. Genome Announc 2:e01147-13

Shiva K (2001) Actinomycetes of an Indian mangrove (Pichavaram) environment: an inventory. Ph.D. thesis, Annamalai University, India, p 91
Short JM, Keller M, Lafferty WM (2003) High throughput or capillary-based screening for a bioactivity or biomolecule. US patent application 2003, S20030049841A1

Simonet P, Bardin R, Haurat J, Moiroud A, Normand P (1986) Localization of nif genes on a large plasmid in Frankia sp. strain ULQ0132105009. Mol Gen Genet 204:492-495

Singh S, Parniske M (2012) Activation of calcium- and calmodulin-dependent protein kinase (CCaMK), the central regulator of plant root endosymbiosis. Curr Opin Plant Biol 15:444-453

Smith C, Li X, Mize T (2013) Sensitive, high throughput detection of proteins in individual, surfactant stabilized picoliter droplets using NanoESI mass spectrometry. Anal Chem 8:2-19

Soltis DE, Soltis PS, Morgan DR, Swensen SM, Mullin BC, Dowd JM, Martin PG (1995) Chloroplast gene sequence data suggest a single origin of the predisposition for symbiotic nitrogen fixation in angiosperms. Proc Natl Acad Sci U S A 92:2647-2651

Svistoonoff S, Laplaze L, Auguy F, Runions J, Duponnois R, Haseloff J, Franche C, Bogusz D (2003) Cg12 expression is specifically linked to infection of root hairs and cortical cells during Casuarina glauca and Allocasuarina verticillata actinorhizal nodule development. Mol Plant Microbe Interact 16:600-607

Takarada H, Sekine M, Kosugi H, Matsuo Y, Fujisawa T, Omata S, Kishi E, Shimizu A, Tsukatani N, Tanikawa S, Fujita N, Harayama S (2008) Complete genome sequence of the soil actinomycete Kocuria rhizophila. J Bacteriol 190:4139-4146

Tanaka Y, Omura S (1993) Agroactive compounds of microbial origin. Annu Rev Microbiol 47:57-87

Tokala RK, Strap JL, Jung CM, Crawford DL, Salove MH, Deobald LA, Bailey JF, Morra MJ (2002) Novel plant-microbe rhizosphere interaction involving Streptomyces lydicus WYEC108 and the pea plant (Pisum sativum). Appl Environ Microbiol 68:2161-2171

Twigg P, An C, Mullin BC (1990) Nucleotide sequence of nif $\mathrm{D}$, the structural gene coding for a subunit of the Mo-Fe protein of the nitrogenase complex from the actinomycete Frankia. In: Gresshoff PM, Roth LE, Stacey G, Newton WE (eds) Nitrogen fixation achievements and objectives. Chapman and Hall, New York, p 771

Vikram S, Kumar S, Subramanian S, Raghava GPS (2012) Draft genome sequence of the nitrophenoldegrading actinomycete Rhodococcus imtechensis RKJ300. J Bacteriol 194:3543

Wang L, Hou Y, Peng J, Qi X, Zhang Q, Bai F (2012a) Bioactivity-based HPLC tandem Q/TOF for alphaglucosidase inhibitors: screening, identification and quantification from actinomycetes. Lat Am J Pharm 31:693-698

Wang L, Wang S, He Q, Yu T, Li Q, Hong B (2012b) Draft genome sequence of Streptomyces globisporus 
C-1027, which produces an antitumor antibiotic consisting of a nine-membered enediyne with a chromoprotein. J Bacteriol 194:4144

Xu L, Huang H, Wei W, Zhong Y, Tang B, Yuan H, Zhu L, Huang W, Ge M, Yang S, Zheng H, Jiang W, Chen D, Zhao GP, Zhao W (2014a) Complete genome sequence and comparative genomic analyses of the vancomycin-producing Amycolatopsis orientalis. BMC Genomics 15:363

Xu Z, Xia J, Feng X, Li S, Xu H, Bo F, Sun Z (2014b) Genome sequence of Streptomyces albulus PD-1, a productive strain for epsilon-poly-L-lysine and poly-L diaminopropionic acid. Genome Announc 2:e00297-14

Yang H, He T, Wu W, Zhu W, Lu B, Sun W (2013) Whole-genome shotgun assembly and analysis of the genome of Streptomyces mobaraensis DSM 40847, a strain for industrial production of microbial transglutaminase. Genome Announc 1:e0014313

Yang H, Zhang Z, Yan R, Wang Y, Zhu D (2014) Draft genome sequence of Streptomyces sp. strain PRh5, a novel endophytic actinomycete isolated from dongxiang wild rice root. Genome Announc 2:e12-e14
Zaburannyi N, Rabyk M, Ostash B, Fedorenko V, Luzhetskyy A (2014) Insights into naturally minimised Streptomyces albus J1074 genome. BMC Genomics 15:97

Zahran HH (2001) Rhizobia from wild legumes: diversity, taxonomy, ecology, nitrogen fixation and biotechnology. J Biotechnol 91:143-153

Zhai Y, Cheng B, Hu J, Kyeremeh K, Wang X, Jaspars M, Deng H, Deng Z, Honga K (2015) Draft genome sequence of Streptomyces sp. strain CT34, isolated from a Ghanaian soil sample. Genome Announc 3: e01508-e01514

Zhang W, Wang L, Kong L, Wang T, Chu Y, Deng Z, You D (2012) Unveiling the post-PKS redox tailoring steps in biosynthesis of the type II polyketide antitumor antibiotic xantholipin. Chem Biol 19:422-432

Zhang H, Zhou W, Zhuang Y, Liang X, Liu T (2013) Draft genome sequence of Streptomyces bottropensis ATCC 25435, a bottromycin-producing actinomycete. Genome Announc 1:e00019-13 